\title{
The Change Imperative: Accelerating the pace of biodiversity discovery and documentation
}

\author{
Hamish Holewa ${ }^{\ddagger}$, Lee Belbin§, Elycia Wallis \\ ‡ Atlas of Living Australia, CSIRO, Canberra, Australia \\ § Blatant Fabrications Pty Ltd, Carlton, Australia \\ | Atlas of Living Australia, CSIRO, Melbourne, Australia
}

Corresponding author: Elycia Wallis (ely.wallis@csiro.au)

Received: 03 Jul 2018 | Published: 05 Jul 2018

Citation: Holewa H, Belbin L, Wallis E (2018) The Change Imperative: Accelerating the pace of biodiversity discovery and documentation. Biodiversity Information Science and Standards 2: e28131.

https://doi.org/10.3897/biss.2.28131

\section{Abstract}

Taxonomic work is slow and time consuming. Alarm bells have rung for years about the need to go faster, the need to attract and train new taxonomic workers, and the need to convince other branches of science that taxonomic work is vital. Morphological taxonomy is either being overrun or augmented - depending on your perspective - by genomics, artificial intelligence, new imaging methods and species-related data from other branches of science.

Ecology is one such branch of science, where defining, documenting and managing information about species traits has emerged as one of the most significant problems in the discipline. Traits have been recorded for aeons, but the resulting data has largely been insulated within cliques. How do we integrate these data and make them available in a form that will help to address significant issues about our environment? The 'speed bumps' on the route to a useful solution may be more social than technical.

Cross-disciplinary collaboration is required to address the big questions in biodiversity research today, and it will need to extend beyond taxonomy and ecology to other disciplines, such as pharmacology and material science. As Harry Truman said, and John LaSalle often quoted, "It is amazing what you can accomplish if you do not care who gets the credit". 
We are challenged to understand and answer the key questions about the world on which we all depend. What are the challenges and the opportunities to accelerate biodiversity discovery and documentation?

\section{Keywords}

taxonomy, biodiversity, species discovery, documentation

\section{Presenting author}

Hamish Holewa, Lee Belbin, Elycia Wallis

\section{Presented at}

SPNHC+TDWG 2018 Conference

\section{Acknowledgements}

This paper is dedicated to, and in memory of, Dr John La Salle, Director of the Atlas of Living Australia from 2013-2018. 